\title{
Quality of life of patients with first-time AMl: a descriptive study
}

\author{
Mandreker Bahall ${ }^{*}$ and Katija Khan
}

\begin{abstract}
Background: Outcomes following acute myocardial infarction (AMI) may result in death, increased morbidity, and change in quality of life (QOL). This study explores health-related QOL of first-time patients following AMI.

Methods: This cross-sectional study used a sample of patients with first-time AMI experienced between April 2011 and March 2015 at a tertiary health institution. Recruited patients belonged to different post-AMl periods: 210 weeks, 5-22 months, and $>22$ months to 4 years post AMI. Inclusion criteria were not confused and communicating freely. Exclusion criteria were non-contactable, refusing to participate, and deceased. One-on-one interviews were conducted using the validated and pre-tested Quality of Life after Myocardial Infarction (QLMI) questionnaire. QOL of patients after AMI was evaluated at each period. Descriptive, Mann-Whitney U, Kruskal-Wallis, and regression analyses were conducted using SPSS version 24.
\end{abstract}

Results: A total of 534 participant interviews (overall response rate 65.4\%) were conducted. Interviewees were predominantly male (67\%), aged 51-65 years (45\%), Indo-Trinidadian (81.2\%), NSTEMI (64.4\%), and hypertensive (72. 4\%). Overall QOL improved over time and in all domains: Emotional, Physical, and Social. Lower QOL was found among women, patients with NSTEMI, and diabetics in all domains; in patients with hypertension and renal disease in the Physical and Social domains only; and in patients with ischaemic heart disease (IHD) in the Physical domain only. Self-reported stress and lack of exercise were associated with lower QOL while drinking alcohol and eating out were related to better QOL. Hypercholesterolemia, smoking, and ethnicity showed no association with QOL. Declining QOL in the Physical domain with age was also found. The leading components of QOL were selfconfidence and social exclusion (early post AMI), lack of self-confidence (intermediate post AMI), and tearfulness (late post AMI).

Conclusions: QOL in AMI survivors improves over time. Female gender, NSTEMI, diabetes, hypertension, renal disease, stress, and lack of exercise were associated with lower QOL while hypercholesterolemia, smoking, and ethnicity showed no association with QOL. Cardiac rehabilitation and psychological support may enhance earlier increased QOL among survivors, particularly among vulnerable groups.

Keywords: Patients with AMI, QOL, Clinical outcome, Time series

\section{Background}

Major outcome measures of acute myocardial infarction (AMI) include physical, social, and psychological domains [1]. Quality of life (QOL) is dependent not only on health provider factors such as access to medical care [2], cardiovascular risk factors [3], and severity of AMI [3], but also on demographic and psychosocial factors such as age [4], sex [5], educational level [6], income [6],

\footnotetext{
* Correspondence: vmandrakes@hotmail.com

Department of Clinical Medical Sciences, University of the West Indies, St. Augustine, Trinidad, Trinidad and Tobago
}

and family and social support [7]. Following AMI, many patients are left traumatized emotionally and physically [8]. Such feelings and an initial reaction of anxiety are aggravated by the perception that a heart attack could lead to imminent death, a belief that affects patients, relatives, and the community even after receiving adequate medical treatment [9]. Reports of family problems and alterations in family life [10], physical activity phobias [11], depression [12], and stress [12] are common, leading to further decline in physical activity and household economic burden [13]. In contrast, improved clinical 
care leads to a decrease in mortality [14] [15] and improvement in QOL and clinical outcomes [15], which can further increase life expectancy and decrease morbidity [16]. In this regard, it is not enough to add years to a person's life; life must also be added to those years [17].

AMI incidence in South Trinidad is 90.6 per 100,000 population with ethnic variation: 55.3 Afro-Trinidadians and 106.6 Indo-Trinidadians per 100,000 population [18]. CAD ranks among the 10 most common chronic diseases globally and is the number one cause of death [19] [20] in Trinidad and Tobago. Every effort must therefore be given to improve the quality of life of patients with CAD. As stated by the World Health Organization (WHO), "quality of life is defined as individuals' perceptions of their position in life in the context of the culture and value systems in which they live and in relation to their goals, expectations, standards, and concerns" [21]. It incorporates many different aspects of a person's life including: physical, psychological, level of independence, social relations, environmental, and spiritual/religion/personal beliefs [22]. Healthrelated QOL of life is defined as a "multi-dimensional concept that includes domains related to physical, mental, emotional, and social functioning". [23]

Although health-related QOL is an important patient outcome [24], it has not been routinely monitored and measured in local settings. Measuring a patient's QOL is of immense value to determine care and to identify appropriate interventions to optimize care. Over the last few decades, numerous QOL tools have been developed to measure patients' QOL. The Quality of Life after Myocardial Infarction (QLMI) questionnaire, however, was developed specifically for post-AMI patients [25], has shown good reliability [26], and was chosen for use in this study. The purpose of this descriptive crosssectional study was to determine health-related QOL and related factors in patients after AMI at different time periods.

\section{Methods}

\section{Setting}

This study was conducted in a public tertiary health care institution (San Fernando General Hospital) in Trinidad and Tobago (population of 1.3 million people). The institution provides free services covering a variety of investigations, treatment, and follow-up care. Surgical interventions such as angioplasty, open heart surgery, and other mechanical device implants are also provided freely through the Ministry of Health's Cardiac Assistance Programme. However, lifestyle interventions such as exercise, diet, relaxation therapy, cardiac rehabilitation, and psychotherapy, which have all been recognized to improve QOL [27], have not been emphasized.

\section{Participants}

Patients for this study were drawn from the Myocardial Infarction in South Trinidad (MIST) database of patients with first-time AMI admitted between 2011 and 2015 . AMI was defined as the experience of ischemic symptoms with or without significant ECG changes, and a change in troponin level [28]. While QOL status of postAMI patients in Trinidad has not been investigated, relevant studies have been conducted in other countries using a range of different times post AMI: for example, 1 month $(N=160)$ [29], 2 weeks to 3 months [30], 3 months $(N=132)$ [31], 1 to 12 months $(N=4340)$ [32], 6 to 12 months $(N=587)$ [33], 4 years $(N=900)$ [34], and an unknown time period $(N=2950)$ [35]. These studies reveal wide variation in time and sample sizes. With no precedent or existing guidelines for specific time periods, this study utilised three time periods to correspond roughly to shortly after, within 2 years, and after 2 years. Specifically, these were the following: 2 to 10 weeks post AMI (Period 1), 5 to 22 months post AMI (Period 2), and over 22 weeks to 4 years post AMI (Period 3). Inclusion criteria were first-time AMI patients and not confused (ability to understand, think clearly, and make meaningful understandable statements). Exclusion criteria included those who felt physically challenged and unable to attend an interview, unwilling, death, and non-contactable patients (after at least 3 attempts by phone). A breakdown of the patients selected (included and excluded) in each period is depicted in Fig. 1.

\section{Instruments}

Patients with AMI were asked to describe their QOL status using the QLMI questionnaire, which was pilot tested with 10 patients to ensure comfort with the wording and understanding of the questions. The QLMI is a 7-point, frequency-based Likert scale comprising 27 questions covering emotional, physical, and social domains. Lower scores correspond to a lower quality of life. Other data extracted from the MIST database included socio-demographics: age, gender, ethnicity, income, educational attainment, job status, type of AMI (ST-segment elevation myocardial infarction, STEMI; or non-ST-segment elevation myocardial infarction, NSTEMI), and medical history.

Interviews were conducted either at the hospital (with patients who agreed to return to the hospital for the interview), the patient's home, or a location convenient for the patient. Some interviews were conducted on the phone, when the patient preferred this method or could not physically attend the interview. Data extracted were entered in a secured computer database that could be accessed only by the researchers, statistician, and research assistants. 


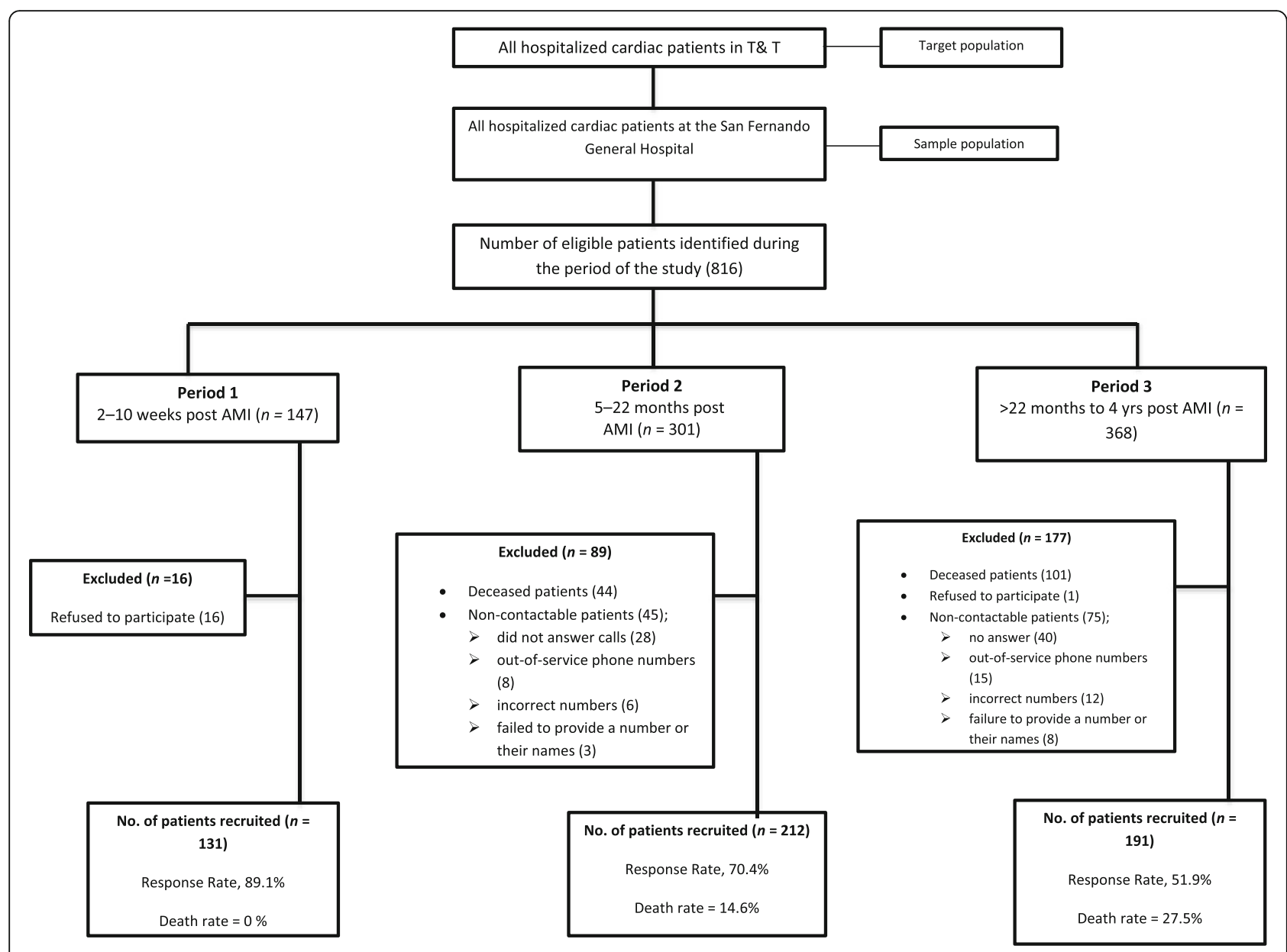

Fig. 1 Participants selection. $\mathrm{AMI}=$ acute myocardial infarction

\section{Analysis}

Data analysis was conducted using SPSS version 24. Given the unequal group sizes and lack of homogeneity of variance among groups, non-parametric tests were used. Mann-Whitney U and Kruskal-Wallis tests were used to compare group differences in scores on QOL and to identify associations with demographic, clinical, and lifestyle factors. Analyses were confined to single factors at a time as combined analysis of multiple variables together was deemed inappropriate because of small sample size and unreliability of subgroup analysis. Linear regression analyses were used to compare test indicators within the different domains of the QLMI, and to identify specific dimensions of Quality of Life most endorsed in the different time periods.

\section{Results}

The response rate was $65.4 \%(n=816)$. Mortality rate was highest $(27.4 \%)$ in the period from $>22$ months to 4 years, followed by $14.6 \%$ in the period from 5 to 22 months. Patient interviewees were predominantly male $(n=342,67 \%)$, aged $51-65$ years $(n=126,45 \%)$,
Indo-Trinidadian $(n=417,81.2 \%)$, NSTEMI $(n=255$, $64.4 \%)$, and hypertensive $(n=329,72.4 \%)$. The mean age of the sample was 60.57 years $(\mathrm{SD}=12.56)$. Participants were further categorised into ages 29-50, 51-65, and > 65 years. There were no significant differences by gender or ethnicity among the age categories (see Table 1 ).

\section{QOL and post AMI time periods}

Using a Kruskal-Wallis $\mathrm{H}$ test, statistically significant differences were observed in all QOL domains in each period: Emotional $\left(\chi^{2}(2)=48.79, p<.001, n=486\right)$, Physical $\left(\chi^{2}(2)=55.68, \mathrm{p}<.001, n=482\right)$, Social $\left(\chi^{2}(2)=\right.$ $85.51, \mathrm{p}<.001, n=485)$, and overall/total QOL $\left(\chi^{2}(4)=\right.$ $55.68, \mathrm{p}<.001, \mathrm{n}=482)$. QOL scores were highest in the $>22$ months to 4 years survivor group followed by the 5-22 months survivor group, with the early post-AMI group (2-10 weeks) having the lowest QOL scores. This trend was observed across all the QOL domains (Fig. 2).

\section{QOL and demographic factors}

Self-reported QOL was higher for males $(n=318)$ than females $(n=198)$ in all domains: Emotional $(\mathrm{U}=$ 
Table 1 Demographic, clinical, and lifestyle characteristics of the sample

\begin{tabular}{|c|c|c|c|c|c|c|c|}
\hline \multirow[b]{2}{*}{ Description } & \multicolumn{2}{|c|}{ 2-10 wks post Ml } & \multicolumn{2}{|c|}{ 5-22 mths post Ml } & \multicolumn{2}{|c|}{$>22$ months -4 yrs. post Ml } & \multirow{2}{*}{$\frac{\text { Total }}{n}$} \\
\hline & $\mathrm{n}$ & $\%$ & $n$ & $\%$ & $n$ & $\%$ & \\
\hline \multicolumn{8}{|l|}{ Gender } \\
\hline Male & 63 & 48.1 & 151 & 71.2 & 128 & 67 & 342 \\
\hline Female & 68 & 51.9 & 61 & 28.8 & 63 & 33 & 192 \\
\hline Total & 131 & 100 & 212 & 100 & 191 & 100 & 534 \\
\hline \multicolumn{8}{|l|}{ Age group (years) } \\
\hline $29-50$ & 25 & 19.1 & 42 & 19.8 & 36 & 18.8 & 147 \\
\hline $51-65$ & 60 & 45.8 & 105 & 49.5 & 86 & 45 & 126 \\
\hline$>65$ & 46 & 35.1 & 65 & 30.7 & 69 & 36.1 & 137 \\
\hline Total & 131 & 100 & 212 & 100 & 191 & 100 & 534 \\
\hline \multicolumn{8}{|l|}{ Ethnicity } \\
\hline Indo-Trinidadian & 89 & 67.9 & 173 & 81.6 & 155 & 81.2 & 417 \\
\hline Afro-Trinidadian & 22 & 16.8 & 27 & 12.7 & 31 & 16.2 & 80 \\
\hline Mixed-Trinidadian & 20 & 15.3 & 12 & 5.7 & 5 & 2.6 & 37 \\
\hline Total & 131 & 100 & 212 & 100 & 191 & 100 & 534 \\
\hline \multicolumn{8}{|l|}{ AMl } \\
\hline STEMI & 17 & 13.0 & 124 & 58.5 & 68 & 35.6 & 209 \\
\hline NSTEMI & 44 & 33.6 & 88 & 41.5 & 123 & 64.4 & 255 \\
\hline Missing & 70 & 46.6 & 0 & 0 & 0 & 0 & 70 \\
\hline Total & 131 & 100 & 212 & 100 & 191 & 100 & 534 \\
\hline \multicolumn{8}{|l|}{ Clinical factors } \\
\hline Diabetes & 57 & 43.5 & 135 & 63.7 & 106 & 58.6 & 279 \\
\hline Hypertension & 65 & 49.6 & 151 & 71.2 & 131 & 72.4 & 329 \\
\hline Hypercholesterolemia & 49 & 37.4 & 29 & 13.7 & 53 & 29.3 & 105 \\
\hline Ischemic heart disease & 35 & 26.7 & 101 & 47.6 & 79 & 44.4 & $2116-$ \\
\hline Kidney problems & 11 & 8.4 & 35 & 16.5 & 19 & 9.9 & 65 \\
\hline \multicolumn{8}{|l|}{ Lifestyle factors } \\
\hline Smoking & 28 & 21.4 & 25 & 11.8 & 15 & 7.9 & 68 \\
\hline Alcohol & 48 & 36.6 & 78 & 36.8 & 79 & 41.4 & 205 \\
\hline Stress & 30 & 22.9 & 60 & 28.3 & 63 & 33.3 & 153 \\
\hline Eating out ( $\geq 1 /$ week) & 7 & 5.3 & 32 & 15.1 & 48 & 25.1 & 86 \\
\hline Exercise ( $\geq 20$ mins/wk) & 30 & 22.9 & 68 & 32.1 & 77 & 30.3 & 172 \\
\hline
\end{tabular}

22,319.5, $p=0.003)$, Physical $(\mathrm{U}=21,914.0, \mathrm{p}=0.003)$, Social $(\mathrm{U}=23,765.5, \quad p=0.048)$, and overall $(\mathrm{U}=$ 21,397.5, $p=0.004)$. Although Afro-Trinidadians had higher median scores than Indo-Trinidadians and the mixed group, there were no statistically significant differences in QOL domains by ethnicity: Emotional ( $\chi 2(2)$ $=3.79, p=.150, n=486)$, Physical $(\chi 2(2)=1.55, p=.460$, $n=482)$, Social $(\chi 2(2)=2.56, p=.279, n=485)$, and overall/total QOL $\left(\chi^{2}(2)=2.23, p=.329, n=476\right)$. With respect to age groups, significant differences were only found for the Physical domain $\left(\chi^{2}(2)=13.686, p=0.001\right)$ and Total scores $\left(\chi^{2}(2)=7.652, p=0.027\right)$. The trend in scores show the lowest QOL scores for the oldest age group (> 65 years) when compared to the younger age groups (Fig. 3).

\section{QOL and clinical factors}

Clinical factors exerted a varying effect on the different aspects of QOL. Between the two types of AMI (STEMI and NSTEMI), there were significant group differences for Emotional $(\mathrm{U}=19,123.500, p=0.002)$, Physical $(\mathrm{U}=19,304.000, \quad p=0.005)$, Social $\quad(\mathrm{U}=$ 20,175.000, $p=0.021)$, and Total QOL $(\mathrm{U}=18,557, p=$ $0.003)$, such that patients with STEMI had significantly 


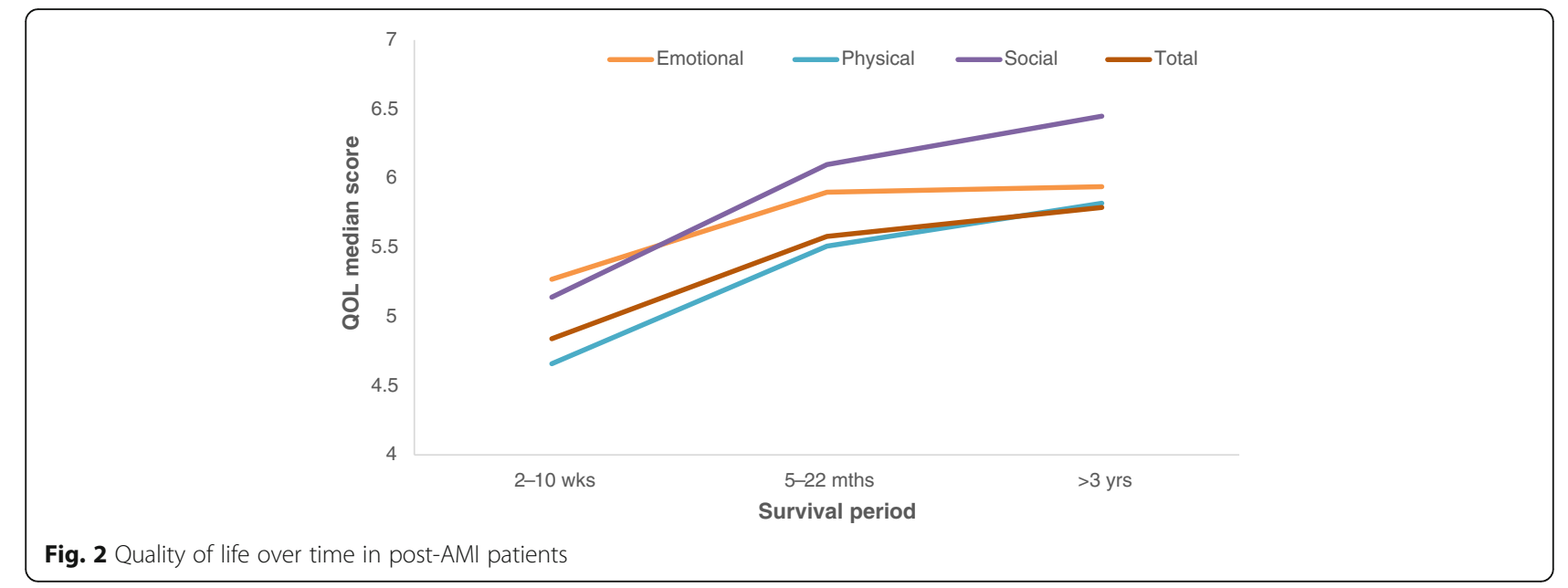

better QOL scores than patients with NSTEMI. Patients with diabetes $(n=275)$ had significantly lower QOL scores than patients without diabetes $(n=170)$ in all domains: Emotional ( $\mathrm{U}=20,648, p=0.038)$, Physical $(\mathrm{U}=18,659, p=0.001)$, Social $(\mathrm{U}=17,782, p<0.001)$ and total QOL $(\mathrm{U}=18,655, p=0.002)$. Patients with hypertension had significantly lower scores in the Physical domain $(\mathrm{U}=16,126, p=0.003)$, Social domain $(\mathrm{U}=17,104, p=0.018)$, and Total QOL $(\mathrm{U}=16,459, p=$ 0.016), but not the Emotional domain. Similarly, patients with kidney problems had significantly lower scores than patients with no kidney problems for the Physical domain $(\mathrm{U}=8323, \mathrm{p}=0.003)$, Social domain $(\mathrm{U}=8751, \mathrm{p}=0.016)$, and Total QOL $(\mathrm{U}=8181$, $p=0.005)$, but not the Emotional domain. Patients with IHD differed significantly only for the Physical domain in which they had significantly lower scores $(\mathrm{U}=20,187, p=0.021)$. No significant differences were observed for QOL between patients with or without hypercholesterolemia.

\section{QOL and lifestyle factors}

A Mann-Whitney $U$ analysis revealed eating out once a week or more was associated with significantly higher QOL in the Physical ( $\mathrm{U}=11,640, p=0.001)$, Social $(\mathrm{U}=$ $11,446, p<0.001)$, and Total QOL $(\mathrm{U}=12,143, p=$ 0.004) domains, but not the Emotional domain. Patients with a self-reported stressful life had significantly lower median scores in all domains of QOL: Emotional $(\mathrm{U}=$ $15,094, p<0.001)$, Physical $(\mathrm{U}=17,421, \mathrm{p}<0.001)$, Social $(\mathrm{U}=19,612, p=0.015)$ and overall/total scores $(\mathrm{U}=$ $16,696, \mathrm{p}<0.001)$. Patients who exercised had significantly higher QOL scores in all domains compared to patients who did not exercise: Emotional $(\mathrm{U}=18,533$, $\mathrm{p}$ $<0.001)$, Physical $(\mathrm{U}=16,921, \mathrm{p}<0.001)$, Social $(\mathrm{U}=$ 18,282, $\mathrm{p}<0.001)$, and Total domains $(\mathrm{U}=16,732, \mathrm{p}<$ $0.001)$.

QOL scores were similar across all domains except the Physical domain, in which alcohol users (median =6.00) reported significantly higher Physical QOL scores than non-drinkers $\quad($ median $=5.79) \quad(\mathrm{U}=24,224, \quad p=0.016)$.

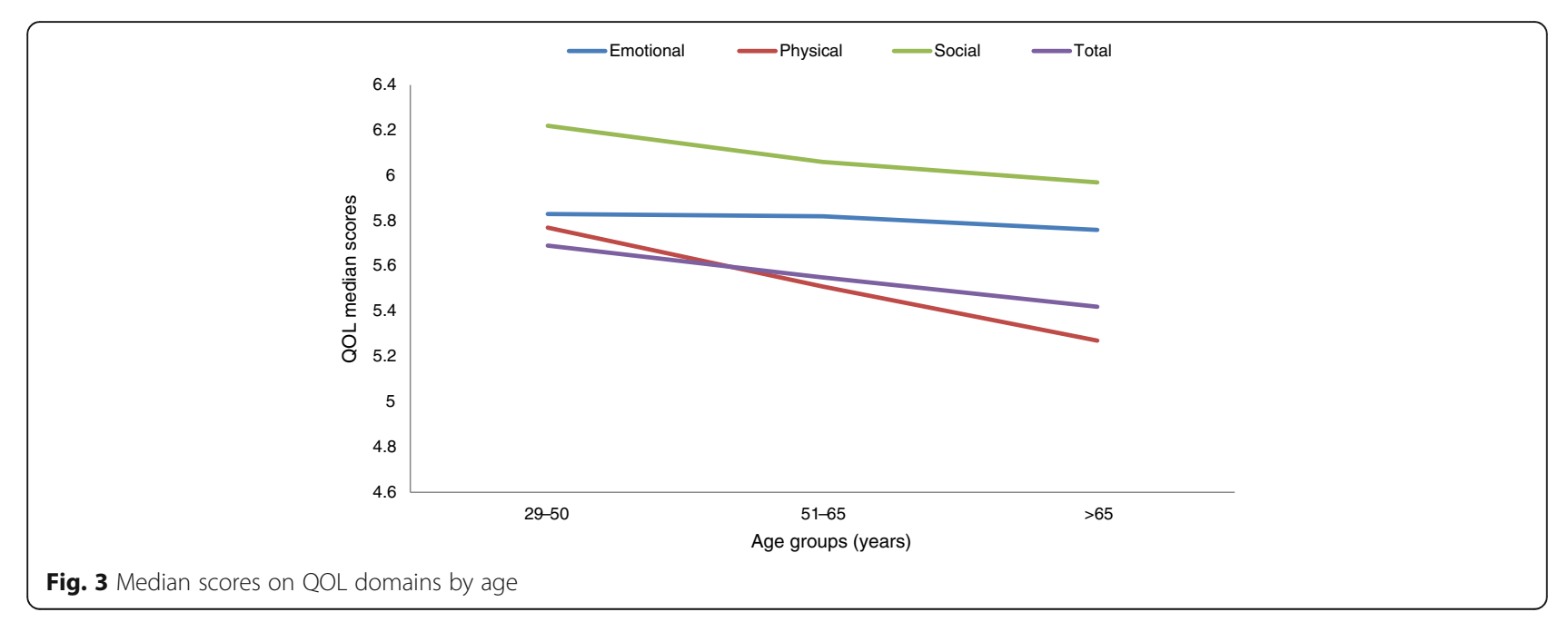


There was no significant difference in QOL of life scores between smokers and non-smokers for any of the domains: Emotional $(\mathrm{U}=12,302, p=.768)$ Physical $(\mathrm{U}=$ $11,100, p=.381)$, Social $(\mathrm{U}=12,125, p=.785)$ and Total domains $(\mathrm{U}=11,228, p=.567)$.

\section{Components of QOL at different time periods}

The leading components of QOL were compared in the three post-AMI periods (early, 2-10 weeks; intermediate, 5-22 months; and late, $>22$ months to 4 years) using linear regression analyses. In the early period, the leading items were "lack of self-confidence" (Emotional domain), "felt excluded" (Physical domain), "felt restricted or limited" (Social domain), and "felt excluded" (Total QOL). In the intermediate period, "lack of self-confidence" for the Emotional domain, and "felt restricted or limited" for the Physical, Social, and total QOL domains, explained the most variance. In the late period (> 22 months to 4 years), "tearfulness", "unable to socialise", "felt excluded", and "unable to socialise" were the leading items for the Emotional, Physical, Social, and total QOL domains, respectively (see Table 2).

\section{Discussion}

QOL was found to improve with time following AMI. It was lowest in the first few weeks following AMI, but showed gradual improvement in all QOL domains (physical, emotional, and social) over time with males enjoying better QOL. This finding is consistent with other studies which have demonstrated improvement as time progresses in QOL post AMI [33]. Patients who suffer from NSTEMI, diabetes mellitus, hypertension, and kidney disease (physical and social domain), and IHD (physical domain) had worse QOL. Lifestyle factors such as eating out (once a week), exercising, and alcohol usage were associated with better QOL. Specific QOL item components that accounted for the greatest variance in the early post-AMI period in QOL were lack of confidence, social exclusion, as well as physical restriction or limitation to perform physical activities.

Improved QOL after 1 year compared to 1 week and 5 months was reported by Brink et al. [36]. The lower QOL experienced in the earlier periods post AMI may result from the immediate shock of patients being diagnosed with a heart attack which to many spells doom, despair, lack of energy [37], apprehension [38], shame [39], guilt [39], depression [40], anxiety [40], job loss [41] [42], loss of income [43], and loss or curtailment of social and family life [44]. Interventions to improve QOL in the immediate post-AMI period are therefore critical since psychological and physical counselling and rehabilitation improve clinical outcomes, physical and otherwise [45].
This study identified lack of confidence, tearfulness, social exclusion, inability to socialise, as well as physical restriction or limitation to perform physical activities as some of the main individual items impacting QOL. These variables have also been identified by De Gucht et al. [46]. These may have come about from the efforts of patients to readjust and rehabilitate themselves in the ensuing period of recovery over time [34] [47] [48].

\section{Age, ethnicity, gender, and QOL}

Male patients experienced better QOL as was also found by Dueñas et al. [49]. This may be attributed to males receiving better social support than females as was also reported by Emery et al. [50]. Our study revealed no significant ethnic differences. This contrasts with the reports of Riegel et al. who reported QOL differences among ethnicities (Hispanics, blacks, and whites) [51]. The authors attribute these differences to cultural differences in interpretation of the QOL items. In this study, it is suggested that both the interpretation and experience of QOL are similar across the Indo-Trinidadian, Afro-Trinidadian, and mixed ethnicities.

\section{Clinical factors and QOL}

Significant differences existed between patients with STEMI, diabetes mellitus, hypertension, kidney disease, and IHD, but not hypercholesterolemia. Patients with STEMI had significantly higher median QOL scores than patients with NSTEMI. It has been noted that the size of myocardial damage is related to QOL [52]. This, however was not reflected in this study, in which patients with STEMI and more muscle damage experienced a better QOL (higher median QOL scores) than patients with NSTEMI, as was also reported by Shah et al. [53]. Patients with NSTEMI may be more symptomatic and experience more angina pectoris. Improved QOL is possible when appropriate surgical interventions, drug interventions, counselling, etc. are instituted [54]. There were mixed results with respect to common chronic diseases in this study. In the Physical, Social, and Emotional domains, patients with diabetes had significantly lower QOL scores than patients without diabetes, a finding that was corroborated by Simpson and Pilote [1]. Significant group differences were observed in the Physical and Social domains among patients with kidney disease and hypertension. These contrast with the findings of Wehner and Nitardy, who found that chronic kidney disease did not adversely affect the patient's QOL 1 year post AMI [55], but is corroborated by Amin et al. who found worsening renal function was associated with reduced QOL [56]. IHD showed lower QOL in the physical domain only, while no significant differences were observed on any QOL domain for patients with hypercholesterolemia. QOL did not vary with 
Table 2 Top QOL items explaining variance in domain scores for patient groups

\begin{tabular}{|c|c|c|c|c|}
\hline Patient group & Domain & Top 3 items explaining variance in domain scores & R change (\%) & Adjusted $\mathrm{R}^{2}(\%)$ \\
\hline \multirow[t]{12}{*}{ 2-10 wks post $\mathrm{Ml}$} & \multirow[t]{3}{*}{ Emotional } & 15. Lack of self-confidence & 70.1 & \multirow[t]{3}{*}{86.1} \\
\hline & & 10. Tearfulness & 11.5 & \\
\hline & & 2. Worthless or inadequate & 5.0 & \\
\hline & \multirow[t]{3}{*}{ Physical } & 24. Felt excluded & 71.9 & \multirow[t]{3}{*}{87.6} \\
\hline & & 15. Felt restricted or limited & 9.6 & \\
\hline & & 6. Worn out & 6.1 & \\
\hline & \multirow[t]{3}{*}{ Social } & 20. Felt restricted or limited & 70.2 & \multirow[t]{3}{*}{90.3} \\
\hline & & 25. Unable to socialize & 14.3 & \\
\hline & & 15. Lack of self-confidence & 6.1 & \\
\hline & \multirow[t]{3}{*}{ Total } & 12. Felt excluded & 67.7 & \multirow[t]{3}{*}{87.5} \\
\hline & & 15. Lacking self-confidence & 15.4 & \\
\hline & & 10. Tearfulness & 4.4 & \\
\hline \multirow[t]{12}{*}{ 5-22 months post Ml } & \multirow[t]{3}{*}{ Emotional } & 15. Lack of self-confidence & 64.7 & \multirow[t]{3}{*}{85.7} \\
\hline & & 4. Discouraged & 15.7 & \\
\hline & & 8. Restless & 5.3 & \\
\hline & \multirow[t]{3}{*}{ Physical } & 20. Felt restricted or limited & 72.6 & \multirow[t]{3}{*}{87.7} \\
\hline & & 24. Felt excluded & 9.4 & \\
\hline & & 27. Interference with sexual intercourse & 5.7 & \\
\hline & \multirow[t]{3}{*}{ Social } & 20. Felt restricted or limited & 70.1 & \multirow[t]{3}{*}{94.7} \\
\hline & & 12. Unable to do usual social activities & 9.9 & \\
\hline & & 15. Lack of self-confidence & 7.5 & \\
\hline & \multirow[t]{3}{*}{ Total } & 20. Felt restricted or limited & 68.4 & \multirow[t]{3}{*}{88.1} \\
\hline & & 4. Discouraged & 15.5 & \\
\hline & & 12. Unable to do usual social activities & 4.4 & \\
\hline \multirow[t]{12}{*}{$>22$ months to 4 yrs. post Ml } & \multirow[t]{3}{*}{ Emotional } & 10. Tearfulness & 71.1 & \multirow[t]{3}{*}{89.7} \\
\hline & & 7. Happy with personal life & 13.9 & \\
\hline & & 12. Unable to do usual social activities & 4.7 & \\
\hline & \multirow[t]{3}{*}{ Physical } & 25. Unable to socialize & 74.1 & \multirow[t]{3}{*}{90.8} \\
\hline & & 21. Unsure about exercise & 1.05 & \\
\hline & & 27. Interference with sexual intercourse & 6.3 & \\
\hline & \multirow[t]{3}{*}{ Social } & 24. Felt excluded & 89.0 & \multirow[t]{3}{*}{96.4} \\
\hline & & 21. Unsure about exercise & 5.4 & \\
\hline & & 15. Lacking self-confidence & 2.0 & \\
\hline & \multirow[t]{3}{*}{ Total } & 25. Unable to socialize & 77.9 & \multirow[t]{3}{*}{91.7} \\
\hline & & 18. Apprehensive or frightened & 10.9 & \\
\hline & & 9. Short of breath & 2.9 & \\
\hline
\end{tabular}

hypercholesterolemia, which departs from other study findings [57]. Individuals with hypertension and coexisting co-morbidities tend to have lower QOL than those suffering from hypertension alone [58].

\section{Lifestyle factors and QOL}

Eating out once a week or more was significantly associated with higher QOL in all domains when compared to persons who did not eat out as frequently. Numerous studies have reported dysfunctional eating was associated with poor QOL either directly or indirectly; it is associated frequently with significantly lower QOL scores in the Emotional and Social domains [59]. This study, however, did not measure the quality or type of food or the specific frequency of eating out. In addition, eating out may be related to cultural and personal practices [60] and socializing, which can confer QOL benefits and thus account for the finding. Self-reports of having a 
stressful life were significantly related to lower median scores in all domains of QOL for all groups. Stress was found to be directly associated with CAD [61] (INTERHEART study). These findings are consistent with those reported by Tasić et al. who found lower QOL in CAD patients with self-reported stress [62]. QOL scores were similar across the Emotional and Social domains as well as total scores for drinkers and non-drinkers. However, alcohol users reported significantly higher physical QOL scores than non-users. This contrasts with Saatcioglu who found alcohol use was related to poorer QOL among patients with alcohol dependence [63]. While alcohol can be used in times of difficulty, it is also associated with festive occasions and may provide culturally accepted opportunities for socializing [64]. Additionally, the patients in this study did not measure the amount or level of alcohol that they consumed; therefore, low or moderate levels of alcohol use may account for the higher QOL scores. It is also noted that improved QOL was only observed in the physical and not social or emotional domains, and as such, the benefits of alcohol use are restricted. From our study, exercising $20 \mathrm{~min}$ or more per day was associated with higher QOL, which is consistent with reported literature [65] [66]. No significant group differences in QOL were found between smokers and non-smokers, as was found in another study [67].

\section{Limitations}

This is a single centre study; however, the findings are still relevant to a national setting. The ratio of male to female patients was approximately $1: 1$ in the early postMI period, while in the other two groups, it was at least $2: 1$. The study used a cross-sectional design with a different cohort of patients at each time point and thus does not reflect changing QOL of the same patients. The broad range of the time periods may also fail to capture potential changes in QOL that occur during these periods. However, even with different cohorts, as used by other studies, QOL trends can be identified. Combining variables for analysis and consideration of multiple comorbidities, although desirable, was deemed inappropriate due to small sample size.

\section{Conclusion}

Increased post-AMI survival, STEMI, non-diabetic, nonhypertensive, non-kidney disease, no self-reported stress, eating out, and exercise were associated with better QOL in all domains. Ethnicity and hypercholesterolemia were not related to QOL. Alcohol was associated with better Physical QOL but not in the Emotional or Social domains. Better QOL was experienced among males and in the younger age groups. Most QOL variance resulted from lack of self-confidence (early and intermediate post
AMI), social exclusion (early and late post AMI), restricted feelings (intermediate post AMI), and inability to socialize and tearfulness (late post AMI).

Cardiac rehabilitation should be tailored to meet the needs of different subgroups of cardiac patients based on gender, ethnicity, level of socialization, and level of physical activity. Counselling for issues of selfconfidence, social exclusion, and interaction need to be initiated during in-patient stays and continued following hospital discharge. While QOL, a valued outcome, improves over time, cardiac rehabilitation may set the stage for earlier and improved QOL among survivors, particularly among vulnerable groups.

\section{Abbreviations \\ AMI: Acute myocardial infarction; ECG: Electrocardiogram; IHD: Ischaemic heart disease; MIST: Myocardial Infarction in South Trinidad; NSTEMI: Non-ST- elevation myocardial infarction; QLMI: Quality of life myocardial infarction; QOL: Quality of life; STEMI: ST-elevation myocardial infarction; WHO: World Health Organization}

\section{Acknowledgements}

We would like to thank the university students who assisted in data collection.

Funding

Not applicable.

Availability of data and materials

The data that support the findings of this study are available from the corresponding author on request.

\section{Authors' contributions}

MB designed the study, collected the data or supervised data collection, and wrote and edited the manuscript. KK performed statistical analysis and editing. All authors read and approved the final manuscript.

\section{Authors' information}

$\mathrm{MB}$ is a Specialist Medical Officer and lecturer at the School of Medicine at the University of the West Indies (Mt. Hope, Trinidad and Tobago). KK is a psychologist and lecturer in clinical psychology in the School of Medicine at the University of the West Indies (Mt. Hope, Trinidad and Tobago).

\section{Ethics approval and consent to participate}

This study received ethical approval from the Ethics Committee of SouthWest Regional Health Authority and the University of the West Indies. All study participants provided informed consent.

\section{Consent for publication}

Not applicable.

\section{Competing interests}

The authors declare that they have no competing interests.

\section{Publisher's Note}

Springer Nature remains neutral with regard to jurisdictional claims in published maps and institutional affiliations.

Received: 10 July 2017 Accepted: 7 February 2018

Published online: 13 February 2018

References

1. Simpson E, Quality PL. Of life after acute myocardial infarction: a comparison of diabetic versus non-diabetic acute myocardial infarction patients in Quebec acute care hospitals. Health Qual Life Outcomes. 2005;3:80. 
2. Smolderen KG, Spertus JA, Nallamothu BK, Krumholz HM, Tang F, Ross JS, et al. Health care insurance, financial concerns in accessing care, and delays to hospital presentation in acute myocardial infarction. JAMA. 2010;303:1392400.

3. Woo KS, White HD. Factors affecting outcome after recovery from myocardial infarction. Annu Rev Med. 1994;45:325-39.

4. Barakat K, Wilkinson P, Deaner A, Fluck D, Ranjadayalan K, Timmis A. How should age affect management of acute myocardial infarction? A prospective cohort study. Lancet. 1999;353:955-9.

5. Hanratty B, Lawlor DA, Robinson MB, Sapsford RJ, Greenwood D, Hall A. Sex differences in risk factors, treatment and mortality after acute myocardial infarction: an observational study. J Epidemiol Community Health. 2000;54 912-6.

6. Rasmussen JN, Rasmussen S, Gislason GH, Buch P, Abildstrom SZ, Køber L, et al. Mortality after acute myocardial infarction according to income and education. J Epidemiol Community Health. 2006;60:351-6.

7. Leifheit-Limson EC, Reid KJ, Kasl SV, Lin H, Buchanan DM, Jones PG, et al, Changes in social support within the early recovery period and outcomes after acute myocardial infarction. J Psychosom Res. 2012;73:35-41.

8. Singer BA. The psychological impact of a myocardial infarction on the patient and family. Psychother Private Pract. 1987;5(3):53-63.

9. Boersma SN, Maes S. Psychological consequences of myocardial infarction: a self-regulation perspective on health-related quality of life and cardiac rehabilitation. Neth Heart J. 2006;14:335-8.

10. Tselika-Garfe A. Effects of acute myocardial infarction on the patient's and the family's way of life. Noseleutike. 1992;31:190-200.

11. Åhlund K, Bäck M, Sernert N. Fear-avoidance beliefs and cardiac rehabilitation in patients with first-time myocardial infarction. J Rehabil Med. 2013;45:1028-33.

12. Larsen KK. Depression following myocardial infarction-an overseen complication with prognostic importance. Dan Med J. 2013;60:B4689.

13. Karan A, Engelgau M, Mahal A. The household-level economic burden of heart disease in India. Tropical Med Int Health. 2014 May;19(5):581-91.

14. Cowie MR, Anker SD, Cleland JGF, Felker GM, Filippatos G, Jaarsma T, et al. Improving care for patients with acute heart failure: before, during and after hospitalization. ESC Heart Failure. 2014;1(2):110-45.

15. Carlhed R, Bojestig M, Peterson A, Åberg C, Garmo H, Lindahl B. Improved clinical outcome after acute myocardial infarction in hospitals participating in a Swedish quality improvement initiative. Circ Cardiovasc Qual Outcomes. 2009:2:458-64.

16. Saar A, Marandi T, Ainla T, Fischer K, Blöndal M, Eha J. Improved treatment and prognosis after acute myocardial infarction in Estonia: cross-sectional study from a high risk country. BMC Cardiovasc Dis. 2015;15:136.

17. WHO. EMRO. Age-friendly world: adding life to years. Elderly-news Elderly health. Emro.who.int. http://www.emro.who.int/elderly-health/elderly-news/ age-friendly-world-adding-life-to-years.html. Accessed 19 January 2018.

18. Bahall M. Epidemiology of acute myocardial infarction in South Trinidad. WIMJ Open. 2016;3(2):1.

19. World Health Organization. The top 10 causes of death. Fact sheet $N^{\circ} 310$; WHO. Updated Jan 2017. http://www.who.int/mediacentre/factsheets/fs310/ en/. Accessed 05 Jun 2017.

20. Pan American Health Organization. Trinidad and Tobago. Health in the Americas. Edition: country volume. Pan American Health Organization. 2012; 2012 http://www.paho.org/saludenlasamericas/index.php?option=com_ docman\&task=doc view\&gid=149\&ltemid. Accessed 18 Sep 2015

21. WHO. WHOQOL: Measuring quality of life. Who.int. 2018. http://www.who. int/healthinfo/survey/whoqol-qualityoflife/en/. Accessed 20 January 2018.

22. WHO. WHOQOL: Measuring quality of life. Who.int. http://www.who.int/ healthinfo/survey/whoqol-qualityoflife/en/index4.html. Accessed 19 January 2018.

23. Health-Related Quality of Life and Well-Being | Healthy People 2020. Healthypeople.gov. https://www.healthypeople.gov/2020/about/foundationhealth-measures/Health-Related-Quality-of-Life-and-Well-Being. Accessed 24 January 2018

24. Asadi-Lari M, Tamburini M, Gray D. Patients' needs, satisfaction, and health related quality of life: towards a comprehensive model. Health Qual Life Outcomes. 2004;2:32.

25. Valenti L, Lim L, Heller RF, Knapp J. An improved questionnaire for assessing quality of life after acute myocardial infarction. Qual Life Res. 1996;5:151-61.

26. Dempster M, Donnelly M, O'Loughlin C. The validity of the MacNew quality of life in heart disease questionnaire. Health Qual Life Outcomes. 2004;2:6.
27. Feizi A, Ghaderi C, Dehghani MR, Khalkhali HR, Effect SS. Of phase III cardiac rehabilitation and relaxation on the quality of life in patients with cardiac syndrome X. Iran J Nurs Midwifery Res. 2012;17:547-52.

28. Agewall $\mathrm{S}$, Giannitsis $\mathrm{E}$, Jernberg $\mathrm{T}$, Katus $\mathrm{H}$. Troponin elevation in coronary vs. non-coronary disease. Eur Heart J. 2011;32:404-11.

29. Rančić NK, Petrović BD, Apostolović SR, Kocić BN, Health-related IMV. Quality of life in patients after the acute myocardial infarction. Cent Eur J Med. 2013;8(2):266-72.

30. Webster RA, Thompson DR, Larkin D, Mayou RA, Quality MCR. Of life in a mixed ethnic population after myocardial infarction. Eur J Pers Cent Healthc. 2017;5(3)

31. Failde II, Soto MM. Changes in health-related quality of life 3 months after an acute coronary syndrome. BMC Public Health. 2006;6:18.

32. Arnold SV, Chan PS, Jones PG, Decker C, Buchanan DM, Krumholz HM, et al. Translational research investigating underlying disparities in acute myocardial infarction patients' health status (TRIUMPH): design and rationale of a prospective multicenter registry. Circ Cardiovasc Qual Outcomes. 2011; 4:467-76.

33. Beck CA, Joseph L, Bélisle P, Pilote L. QOLAMI investigators (quality of life in acute myocardial infarction). Predictors of quality of life 6 months and 1 year after acute myocardial infarction. Am Heart J. 2001;142:271-9.

34. Brown N, Melville M, Gray D, Young T, Munro J, Skene AM, et al. Quality of life four years after acute myocardial infarction: short form 36 scores compared with a normal population. Heart. 1999;81:352-8.

35. Schweikert B, Hunger M, Meisinger C, König H-H, Gapp O, Holle R. Quality of life several years after myocardial infarction: comparing the MONICA/KORA registry to the general population. Eur Heart J. 2009;30:436-43.

36. Brink E, Grankvist G, Karlson BW, Health-related HLRM. Quality of life in women and men one year after acute myocardial infarction. Qual Life Res. 2005; 14:749-57.

37. Alsén P, Brink E. Fatigue after myocardial infarction - a two-year follow-up study. J Clin Nurs. 2013:22:1647-52.

38. Nymark C, Mattiasson A-C, Henriksson P, Kiessling A. Emotions delay careseeking in patients with an acute myocardial infarction. Eur J Cardiovasc Nurs. 2014;13:41-7.

39. Salminen-Tuomaala M, Astedt-Kurki P, Rekiaro M, Paavilainen E. Coping experiences: a pathway towards different coping orientations four and twelve months after myocardial infarction-a grounded theory approach. Nurs Res Pract. 2012;2012:674783.

40. Mierzyńska A, Kowalska M, Stepnowska M, Piotrowicz R. Psychological support for patients following myocardial infarction. Cardiol J. 2010;17:31924.

41. Dreyer RP, Xu X, Zhang W, Du X, Strait KM, Bierlein M, et al. Return to work after acute myocardial infarction: comparison between young women and men. Circ Cardiovasc Qual Outcomes. 2016:9:S45-52.

42. European Society of Cardiology. One-third of heart failure patients do not return to work: Return to work more likely in men, younger patients, and those with higher education level. 2016. ScienceDaily. www.sciencedaily. com/releases/2016/05/160522144103.htm. Accessed 22 January 2018.

43. Rao SV, Schulman KA, Curtis LH, Gersh BJ, Jollis JG. Socioeconomic status and outcome following acute myocardial infarction in elderly patients. Arch Intern Med. 2004;164:1128-33.

44. Garcia RP, Budó M. De LD, Simon BS, Wünsch S, Oliveira SG, Barbosa M da S. [family experiences post-acute myocardial infarction]. Rev Gaucha Enferm. 2013;34:171-8.

45. Kang K, Gholizadeh L, Inglis SC, Han HR. Interventions that improve healthrelated quality of life in patients with myocardial infarction. Qual Life Res. 2016 Nov:25(11):2725-37.

46. De Gucht V, Van Elderen T, van der Kamp L, Oldridge N. Quality of life after myocardial infarction: translation and validation of the MacNew questionnaire for a Dutch population. Qual Life Res. 2004;13(8):1483-8.

47. Albrecht GL, Devlieger PJ. The disability paradox: high quality of life against all odds. Soc Sci Med. 1999;48:977-88.

48. Sprangers MA, Schwartz CE. Integrating response shift into health-related quality of life research: a theoretical model. Soc Sci Med. 1999;48(11):1507-15.

49. Dueñas M, Ramirez C, Arana R, Failde I. Gender differences and determinants of health related quality of life in coronary patients: a followup study. BMC Cardiovasc Disord. 2011;11:24.

50. Emery CF, Frid DJ, Engebretson TO, Alonzo AA, Fish A, Ferketich AK, et al. Gender differences in quality of life among cardiac patients. Psychosom Med. 2004;66:190-7. 
51. Riegel B, Moser DK, Rayens MK, Carlson B, Pressler SJ, Shively M, et al. Ethnic differences in quality of life in persons with heart failure. J Card Fail. 2008;14 $41-7$.

52. Lane D, Carroll D, Ring C, Beevers DG, Lip GY. Mortality and quality of life 12 months after myocardial infarction: effects of depression and anxiety. Psychosom Med. 2001;63:221-30.

53. Shah P, Najafi AH, Panza JA, Cooper HA. Outcomes and quality of life in patients $\geq 85$ years of age with ST-elevation myocardial infarction. Am J Cardiol. 2009;103:170-4.

54. Takiuti ME, Hueb W, Hiscock SB, Nogueira CRS, Girardi P, Fernandes F, et al. Quality of life after surgical myocardial revascularization, angioplasty or medical treatment. Arq Bras Cardiol. 2007;88(5):537-44.

55. Wehner P, Nitardy W. Chronic kidney disease and acute myocardial infarction: the story after 1 year. J Am Heart Assoc. 2016;5

56. Amin AP, Spertus JA, Reid KJ, Lan X, Buchanan DM, Decker $C$, et al. The prognostic importance of worsening renal function during an acute myocardial infarction on long-term mortality. Am Heart J. 2010;160:1065-71.

57. Mata N, Alonso R, Banegas JR, Zambón D, Brea A, Mata P. Quality of life in a cohort of familial hypercholesterolemia patients from the south of Europe. Eur J Pub Health. 2014;24:221-5.

58. Soni RK, Porter AC, Lash JP, Unruh ML. Health-related quality of life in hypertension, chronic kidney disease, and coexistent chronic health conditions. Adv Chronic Kidney Dis. 2010;17:e17-26.

59. Wayne SJ, Baumgartner K, Baumgartner RN, Bernstein L, Bowen DJ, BallardBarbash R. Diet quality is directly associated with quality of life in breast cancer survivors. Breast Cancer Res Treat. 2006;96:227-32.

60. Food M-RVB. Taboos: their origins and purposes. J Ethnobiol Ethnomed. 2009;5:18.

61. Yusuf S, Hawken S, Ounpuu S, Dans T, Avezum A, Lanas F, et al. Effect of potentially modifiable risk factors associated with myocardial infarction in 52 countries (the INTERHEART study): case-control study. Lancet. 2004;364: 937-52.

62. Tasić I, Lazarević G, Stojanović M, Kostić S, Rihter M, Djordjević D, et al. Health-related quality of life in patients with coronary artery disease after coronary revascularization. Cent Eur J Med. 2013;8(5):618-26.

63. Saatcioglu O, Yapici A, Cakmak D. Quality of life, depression and anxiety in alcohol dependence. Drug Alcohol Rev. 2008:27:83-90.

64. La Rose M. TT loves alcohol. Trinidad and Tobago Newsday. 2015; http:// www.newsday.co.tt/news/0,214726.html. Accessed 06 Feb 2017

65. Benetti M, Araujo CLP. De, Santos RZ dos. Cardiorespiratory fitness and quality of life at different exercise intensities after myocardial infarction. Arq Bras Cardiol. 2010:95:399-404.

66. Gill DL, Hammond CC, Reifsteck EJ, Jehu CM, Williams RA, Adams MM, et al. Physical activity and quality of life. J Prev Med Public Health. 2013:46:S28-34.

67. Buchanan DM, Arnold SV, Gosch KL, Jones PG, Longmore LS, Spertus JA, et al. Association of smoking status with angina and health-related quality of life after acute myocardial infarction. Circ Cardiovasc Qual Outcomes. 2015; 8:493-500.

\section{Submit your next manuscript to BioMed Central and we will help you at every step:}

- We accept pre-submission inquiries

- Our selector tool helps you to find the most relevant journal

- We provide round the clock customer support

- Convenient online submission

- Thorough peer review

- Inclusion in PubMed and all major indexing services

- Maximum visibility for your research

Submit your manuscript at www.biomedcentral.com/submit

) Biomed Central 